\title{
A Canadian Working Group report on fecal microbial therapy: Microbial ecosystems therapeutics
}

\author{
Emma Allen-Vercoe $\mathrm{PhD}^{1}$, Gregor Reid $\mathrm{PhD}^{2}$, Norman Viner $\mathrm{MD}^{3}$, Gregory B Gloor $\mathrm{PhD}^{2}$, \\ Susy Hota MD MSc ${ }^{5}$, Peter Kim $\mathrm{PhD}^{1}$, Christine Lee $\mathrm{MD}^{4}$, Kieran C O'Doherty PhD ${ }^{1}$, \\ Stephen J Vanner MD MSc ${ }^{6}$, J Scott Weese DVM DVSc${ }^{1}$, Elaine O Petrof MD MSc ${ }^{6}$
}

\begin{abstract}
E Allen-Vercoe, G Reid, N Viner, et al. A Canadian Working Group report on fecal microbial therapy: Microbial ecosystems therapeutics. Can J Gastroenterol 2012;26(7):457-462.
\end{abstract}

\begin{abstract}
A working group from across Canada comprised of clinician and basic scientists, epidemiologists, ethicists, Health Canada regulatory authorities and representatives of major funding agencies (Canadian Institutes of Health Research and the Crohn's and Colitis Foundation of Canada) met to review the current experience with fecal microbial therapy and to identify the key areas of study required to move this field forward. The report highlights the promise of fecal microbial therapy and related synthetic stool therapy (together called 'microbial ecosystems therapeutics') for the treatment of Clostridium difficile colitis and, possibly, other disorders. It identifies pressing clinical issues that need to be addressed as well as social, ethical and regulatory barriers to the use of these important therapies.
\end{abstract}

Key Words: Clostridium difficile; Fecal microbial therapy; Microbiome

\section{Rapport d'un groupe de travail canadien sur la thérapie antimicrobienne fécale : la thérapeutique des écosystèmes microbiens}

\begin{abstract}
Un groupe de travail pancanadien composé de chercheurs cliniciens et fondamentaux, d'épidémiologistes, d'éthiciens, d'organismes de réglementation de Santé Canada et de représentants de grands organismes subventionnaires (Instituts de recherche en santé du Canada et Fondation canadienne des maladies inflammatoires de l'intestin) s'est réuni pour analyser l'expérience à jour en matière de thérapie microbienne fécale et déterminer les principaux domaines d'étude nécessaires pour faire progresser ce secteur. L'analyse souligne le caractère prometteur de la thérapie microbienne fécale et de la coprothérapie synthétique connexe (désignés collectivement «thérapeutique des écosystèmes microbiens ») pour traiter la colite à Clostridium difficile et, peut-être, d'autres troubles. Elle établit des enjeux cliniques pressants qu'il faut aborder ainsi que les obstacles sociaux, éthiques et en matière de réglementation liés à l'utilisation de ces thérapies importantes.
\end{abstract}

lostridium difficile infection (CDI) accounts for $15 \%$ to $25 \%$ of $\checkmark$ cases of antimicrobial-associated diarrhea (1). The epidemiology of CDI has undergone a dramatic change over the past 10 to 15 years, with increasing incidence, severity and relapse rates, and widespread reports of outbreaks in health care facilities. Between 2002 and 2005, a large outbreak of the hypervirulent strain NAP1 in Quebec led to quadrupling of annual CDI incidence compared with baseline rates from 1991 (2,3). Along with shifts in epidemiology, it has been noted that CDI disease is manifesting with heightened severity, leading to more episodes of toxic megacolon, sepsis and death. In one Canadian surveillance study (4), CDI-attributable mortality increased from $1.5 \%$ in 1997 to $5.7 \%$ in 2004. Furthermore, recurrent episodes of disease have become more common. Recurrent CDI, defined as complete resolution of CDI while on appropriate therapy followed by recurrence of infection after treatment has been stopped (5), has become more extensive, leading to a larger burden of morbidity in this population. In a study conducted during the Quebec CDI outbreak (6), initial recurrence rates were as high as $47 \%$. Existing treatment options for recurrent CDI are somewhat limited.

Recurrent CDI is believed to result from the inability of the intestinal microbiota to recover and re-establish itself to homeostasis with the host (we henceforth use the term 'normal' to mean one that does not cause symptoms and signs of infection), after an initial insult, such as antimicrobial exposure $(7-10)$. One treatment that appears highly effective in preliminary studies and anecdotal reports is fecal microbial therapy, also referred to as stool transplant, fecal bacteriotherapy or fecal microbiota replacement. This involves taking stool from a healthy 'donor' and administering it to a patient with recurrent CDI. Hence, the goal of fecal microbial therapy is to re-establish a more normal fecal composition with increased microbial diversity. There is a rapidly growing number of published studies on fecal microbial therapy, with most reporting cure rates of approximately $90 \%(5,11$ 13). However, despite its apparent success, it remains reserved as a last resort treatment for a number of reasons (Table 1).

To address these issues, a two-day Canadian Institutes of Health Research-sponsored meeting was held in Toronto, Ontario, in October 2011, which brought together a diverse group of specialists (Figure 1). Because 'synthetic stool', composed of large numbers of well-defined bacterial strains derived from stool, has also been reported to be effective, the term 'microbial ecosystem therapeutics' (MET) was proposed as a more accurate scientific description for the treatment. Fecal microbial treatments, in one form or another, have been performed in at least six major cities in Canada and, in total, the attendees at the meeting collectively performed more than 220 stool transplants, which is likely a major underestimation of the true number that have been performed in Canada.

The present article summarizes the meeting proceedings in two parts: an overview of current practices and challenges in Canada; and priorities for future studies.

\section{OVERVIEW OF CURRENT PRACTICES AND CHALLENGES IN CANADA}

Epidemiology of CDI in Canada - what are the missing pieces? The Canadian Nosocomial Infection Surveillance Program tracks hospital-associated CDI epidemiology from selected participant hospitals and monitors strain predominance. However, there are significant limitations to the quantity and quality of data this national surveillance program can provide. Along with the changing epidemiology of hospital-associated CDI, there has been an increase in communityassociated CDI, including severe disease in young people with few or no traditional risk factors. There is surprisingly little information available about the prevalence and epidemiology of $\mathrm{C}$ difficile colonization

\footnotetext{
${ }^{1}$ University of Guelph, Guelph; ${ }^{2}$ University of Western Ontario and Lawson Health Research Institute, London; ${ }^{3}$ Health Canada, Ottawa;

${ }^{4} \mathrm{McM}$ aster University, Hamilton; ${ }^{5}$ University of Toronto, Toronto; 6 Queen's University, Kingston, Ontario

Correspondence: Dr Elaine O Petrof, Department of Medicine/Infectious Diseases, Gastrointestinal Diseases Research Unit, Queen's University,

76 Stuart Street, Gastrointestinal Diseases Research Unit Wing, Kingston, Ontario K7L 2V7. Telephone 613-549-6666 ext 6516, fax 613-548-2426,

e-mail eop@queensu.ca

Received for publication March 20, 2012. Accepted April 5, 2012
} 


\section{TABLE 1}

\section{Unresolved questions about fecal microbial therapy}

1. Are there sufficient data to support its widespread adoption as a treat-
ment for recurrent CDI?
2. What is the best method for preparing and delivering the treatment?
3. Can it be standardized?
4. How can safety be optimized?
5. What is/are the optimal combination(s) of bacterial strains necessary to
restore the microbial balance to treat recurrent CDI?
6. Are there other components in fecal material that are equally or more
important for cure of recurrent CDI than the microbes?
7. Are there better ways of accomplishing microbiota reconstitution, such as
use of synthetic stool transplants?

$C D I$ Clostridium difficile infection

in people in the community, which hampers our understanding of transmission of this pathogen. Spread of $\mathrm{C}$ difficile between humans in the general population is a potential source; however, contacts with animals, food, water and the environment are other modes of acquisition of the organism. For example, ribotype 078 is a hypervirulent strain that predominates in food animals and can be found in retail food products (including meat, vegetables and fish) (14-16). Concern has been expressed that food may be a source of exposure (17), and increases in the prevalence of 078 have been reported internationally (18-20). The impact of different strains of $\mathrm{C}$ difficile on recurrent CDI is not well studied because most hospitals do not routinely perform culture and strain typing. Another important concern is that not all hospitals track recurrent cases and, hence, there is very limited information available about the national epidemiology of recurrent CDI.

MET donor issues: source of material and screening

The majority of the physicians performing MET in Canada obtain the stool donation from a close family member or spouse of the patient. Before the donation, this individual is thoroughly screened for bloodborne and enteric pathogens. Most commonly, this entails screening for: HIV-1 and -2, hepatitis A, B and C viruses, syphilis, enteric bacteria (Salmonella species, Shigella species, Campylobacter species, Escherichia coli 0157-H7 and Yersinia), presence of ova and parasites, and $\mathrm{C}$ difficile toxin in the stool. Some centres also check for donor colonization with Helicobacterpylori, methicillin-resistant Staphylococcus aureus and vancomycin-resistant Enterococcus species (in stool). Many clinicians perform a risk assessment that includes high-risk behaviours for blood-borne pathogens, a thorough detailed history and physical examination, and test for sexually transmitted infections.

Most of the physicians at the meeting who administer MET did not note any obvious relationship of the stool donor to success in the recipient; however, objective studies are lacking. Some major challenges in donor screening were identified. First, the results of the screening tests take several days (sometimes more than two weeks) to be obtained, and treatment cannot be administered until the results of the screening tests are available. Second, although donors are screened as close as possible to the time that they donate, there is time between sampling and donation during which donors could feasibly become infected with a pathogen. Therefore, asymptomatic donors could unwittingly pass an infection on to the patient through stool transplant. Third, the laboratory cost of screening one donor in Canada is approximately $\$ 95$ to $\$ 100$, plus additional laboratory fees including processing costs of the transplant stool sample. Finally, current donor screening protocols only test for the common and known pathogens that may be transmitted through stool and blood, and it is possible that other organisms could jeopardize the long-term success of the transplant.

The possibility that gut bacteria regarded as commensal may have disease-inducing potential in some individuals is being explored. For example, if certain bacterial profiles are associated with colorectal

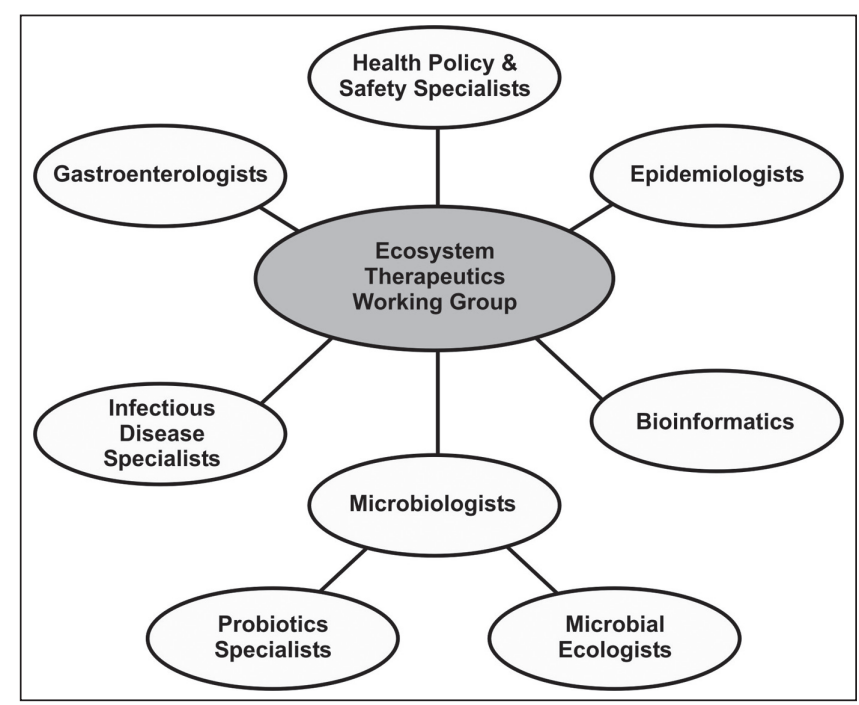

Figure 1) A Canadian Working Group report on fecal transplant therapy: Microbial ecosystems therapeutics

cancer $(21,22)$, their transplantation may have future consequences for the recipient. Should such species have carcinogenic properties, these may not manifest themselves until years after treatment. Thus, these theoretical and unknown risks should be explained to the patient so they are fully aware that the long-term effects of fecal transplantation remain largely unknown.

Another approach used at one centre is to prescreen a few select donors unrelated to the patients. This may provide a consistent source of donor material and one that can be used within one to two days of identifying a patient in need. Using these donors' stools, 89 patients with recurrent CDI at one centre have undergone fecal transplant therapy. The inpatients received the treatment within $48 \mathrm{~h}$ and the outpatients within seven days of being referred for MET. Eighty-two of $89(92.1 \%)$ patients experienced clinical cure at six- to 24 -month follow-up. However, as with regular donors, the theoretical risk of the single donor becoming infected with a communicable disease still exists. One way to potentially avoid this problem may be to freeze aliquots of stool from a single, screened donor for future use. Although concerns were raised about possible loss of fastidious organisms if frozen material were used, a study conducted in the United States has already reported success with this approach (23).

One group has published a 'do-it-yourself' approach in a peerreviewed journal (24), wherein the donor is screened by the physician and then 'advised' how to perform the procedure at home. Although it raises additional clinical, social and ethical issues, this approach evolved from a strong clinical need for patients who were refractory to all other treatment options. It has been used quite extensively, particularly by physicians whose hospitals have refused to support MET as a treatment for recurrent CDI.

The use of a 'synthetic stool' approach has been evaluated at one centre. Bacterial strains were purified from a single (unrelated) donor, grown in culture and subsequently administered as a suspension in sterile normal saline (25). The expanding interest in the human gut microbiome and new technologies have led to more gut bacterial species being cultured in vitro, making it possible to combine complex and defined mixtures of cultured isolates that are more representative of the native stool microbiota. Preliminary data from this centre are encouraging, but broader study is needed.

The manufacturing of a probiotic ecosystem consisting of usually fastidious, mostly anaerobic microbial species as an alternative to stool transplantation can be accomplished using a chemostat. This allows growth of component species together in continuous culture, under conditions that resemble the gut. For decades, microbial ecologists 
have used chemostats to achieve optimal growth of microbes, and conditions imitating the gut microenvironment have been well defined using such systems $(26,27)$. Chemostat cultures could have several advantages over the single-donor approach; administration of a defined bacterial formulation/product proven to have been effective in the past, cost savings associated with simplified treatment protocols and decreased cost of donor screening tests. The risk of contamination with viruses and other pathogens would be greatly reduced and antimicrobial susceptibility profiling can be performed easily on bacterial isolates, ensuring that they can be eradicated if the need for this should ever arise. The use of in vitro culture of bacterial isolates has been viewed as the next logical step in the development of recurrent CDI treatment $(5,10,12)$.

\section{Preparation of material}

While some sites use a Stomacher Lab Blender (Seward Laboratory Systems Inc, USA) to prepare the material, because of the cost, most use regular household blenders, which are then autoclaved and discarded after use. The amount of fecal material used varies from $50 \mathrm{~g}$ to $100 \mathrm{~g}$ per treatment, in volumes that range from $50 \mathrm{~mL}$ to more than $1 \mathrm{~L}$. A general consensus was reached that $50 \mathrm{~g}$ of stool resuspended in $250 \mathrm{~mL}$ volume works well, when given per rectum. Most sites use normal saline to resuspend the material, and they are not able to perform this under anaerobic conditions in the majority of cases. Lack of support from the hospital and clinical laboratories was identified as a major barrier at several facilities.

\section{Delivery of METs}

Most physicians reported performing this procedure using retention enema as the method of delivery. One reported success delivering the transplant via the upper GI tract, and several at one centre used colonoscopy to deliver the donor material. Some use colon cleansing agents such as $4 \mathrm{~L}$ polyethylene glycol solutions before delivery. All methods appear to be effective, and no complications were reported.

The delivery route for fecal therapy is not only a practical issue but raises interesting mechanistic questions given that the regions of colon in contact with the transplant material can markedly differ. Oral administration via nasojejunal (NJ) tube preferentially delivers the organisms first to the small bowel. While it may cover additional areas of the bowel, the procedure of inserting the NJ tube is uncomfortable, often requires an $\mathrm{x}$-ray confirmation of tube placement and is less palatable to patients. Application through a colonoscope delivers the bacteria to both the right and left colon, which is desirable for surface area coverage. When performed in hospital, however, this method requires availability of a staffed endoscopy suite and is considerably more expensive. Administration by enema - the simplest and least expensive method - reaches only the left colon. In fact, if the fecal enema is administered without any prior colon cleansing, its contents may only reach the distal left colon. If fecal enemas are as efficacious as other modalities, it would suggest that the burden of infection is relatively distal in the colon and/or there is significant proximal migration of the therapeutic organisms. It is not known whether the route of administration has an important influence on efficacy because no studies have been specifically designed to compare different routes of administration. However, a recent systematic review suggests that administration by NJ tube may be inferior to the rectal route (11).

The use of colon cleansing agents administered before colonoscopy may alter the composition and diversity of the intestinal microbiota for several weeks postprocedure (28). Any such changes could influence the effect of therapy and, at the very least, would be a consideration when monitoring changes in the microbiota following therapy.

Understanding the science: the value of bioinformatics analysis of microbial ecosystems in recurrent CDI

There are several approaches to characterize and understand the microbial ecosystems of the distal gut, which range from only descriptive information to providing an assessment of community capabilities and function. 16S ribosomal RNA (rRNA) profiling, accomplished by deep sequencing of polymerase chain reaction-amplified rRNA variable regions using high-throughput sequencing platforms $(29,30)$, is the simplest method and is useful for a descriptive examination or comparison of community composition. Currently, the most commonly used platform is pyrosequencing (HiSeq, Illumina, USA), but newer platforms, such as MiSeq (Illumina, USA) or Ion Torrent (Ion Torrent Systems, USA) are likely to gain traction because of relatively rapid turn-around times. Real-time assessment of the microbiota composition will enable monitoring of colonization of the recipient with the administered MET.

Information from 16S rRNA sequence analysis can be used to characterize the gross composition of the microbiota using tools such as Quantitative Insights Into Microbial Ecology (31). In some cases, it has been possible to identify specific groups of organisms that are strongly associated with a particular condition (32). A barrier identified in this approach is that the ability of microbe composition to be identified depends largely on the database used, the completeness of the database, and the particular variable region(s) amplified and sequenced.

Another approach is whole metagenomic sequencing, wherein the DNA isolated from the entire community is sequenced en masse, allowing the functional capabilities of the community to be identified. Each resulting read is annotated using specialized tools $(33,34)$ and the cumulative data are used to identify the potential metabolic pathways of the community.

Taking this a step further, the actual functional activity of the community can be determined by metatranscriptomic analysis wherein messenger RNA isolated from the community is converted to complementary DNA and sequenced on a high-throughput platform. This requires great care in sample collection and preparation because microbial messenger RNA is very unstable and samples must be immediately placed into a medium that inhibits both new transcription and RNA degradation. Another challenge is the statistical tools themselves, which are often not appropriate to examine differential gene expression from mixed communities (34). However, it was generally agreed that the metatranscriptomic approach will become more widely used once the technical issues are solved because it allows characterization of exactly what genes are being expressed by the organisms in the microbial ecosystem.

\section{Ethical and social issues}

The fact that many hospitals and health authorities do not sanction MET suggests that the treatment may involve important ethical, legal and/or social challenges. It can be argued that the risks to the patient from potential unknown pathogens in donor stool is not substantively different from that of unknown adverse consequences of new drugs or other interventions. Moreover, the argument can be made that in severe cases of illness, such risks are outweighed by the potential benefit to the patient. As outlined previously, this issue may be resolved through adequate informed consent procedures in which the patient understands both known and unknown risks of the intervention. Currently, the consent processes used by clinicians performing MET vary in structure and content, and standardization may help to address these challenges.

Another potential issue is ownership of the donor stool. Traditionally, fecal matter has been considered waste; however, the efficacy of MET suggests value of fecal matter and the microbial communities it contains. In the case of human tissue samples that have been used to develop novel therapies that may potentially lead to a significant financial gain, controversies have developed when patients from whom tissues were originally sourced, objected. In some cases, individuals did not even know that their tissues were used for research or development of novel therapies (35). Similar questions may arise regarding ownership of the microbiome, in particular in the case of donor microbes being used for transplantation or the development of synthetic stool transplants (36). The potential aversion and discomfort not only for the patients, but also for the hospital staff or others 
assisting in the procedure is another important issue. Particularly in the context of strong and persistent social conditioning regarding the handling of feces (ie, it is both 'filthy' and 'dangerous'), it should not be expected that health care providers or the general public will readily accept MET using strictly rational decision-making criteria in the absence of clear communication and education. Any use of MET thus needs to take into account sensitivities of both patients and professionals.

Finally, ethical arguments against performing MET or supporting such procedures on a policy need to be balanced against the risks of not allowing such procedures. Most obviously, given the apparent success of the procedure for CDI and the impact of recurrent CDI on patients, a strong ethical imperative exists for at least considering MET as an option for salvage therapy in patients who have failed all other available treatment modalities. It is also important to recognize that public awareness of fecal transplantation is increasing, together with the option of self-administration. In the absence of screening for pathogens and other safeguards, self- administration is arguably much more risky.

\section{Regulatory aspects: Health Canada's perspective}

According to Health Canada, a drug (or a therapeutic agent) is a substance (or mixture of substances) for which a claim is being made (diagnostic, preventive or therapeutic). Biological drugs (manufactured in, or by, biological or living systems) differ from therapeutic drugs (manufactured using synthetic/chemical processes) in that they are more complex from the perspective of quality review and, thus, have different regulatory requirements.

Deciding where MET fits into the Health Canada Regulatory scheme has not been straightforward. The use of the word 'transplantation' in fecal transplantation has led to some confusion because it implies that this therapy should be considered on par with other, more conventional, transplantations. There is a separate regulatory process for the transplantation of cells, tissues and organs that includes very specific donor screening parameters and prescribed laboratory testing. All of the same standards may not necessarily apply to fecal transplantation or synthetic bacterial culture therapies, but a subset of them are likely relevant. Due to the risks - real and yet to be defined - as well as the therapeutic claims made for fecal transplantation and the fact that METs are derived from human donors, these therapies are not considered as a natural health product. Because it is administered most commonly into the bowel, it also cannot be considered a food, although it has been proposed to consider regulating this therapy in a similar fashion to breastmilk banking. Accordingly, Health Canada considers these therapies as a 'New Biologic Drug'. At Health Canada, submissions for this type of drug fall under the Biologic and Genetics Therapies Directorate (BGTD).

The study of new biological drugs requires a risk-benefit assessment as part of a clinical trial application (CTA) that focuses on the efficacy, safety and quality of the product. The CTA submission undergoes a detailed screening and review by both a clinical and quality stream within the directorate. In addition, the review of biological drugs also requires the following:

1. On-site evaluation to assess the production process and facility to ensure that the manufacturing process conforms to information described in the submission.

2. Additional good manufacturing practice considerations and issues pertinent to manufacturing and control of biological drugs.

3. Lot-release information to ensure consistency via testing samples to confirm potency, purity and safety batch to batch. This is especially important for mixtures as complex as fecal transplantation or synthetic bacterial cultures derived from human feces.

If a CTA submission satisfies these criteria, a 'No Objection Letter' is issued by Health Canada, authorizing the investigators to proceed with the trial. With respect to fecal transplantation, Health Canada requires that donors be assessed and screened for all the infectious diseases that are tested for in organ transplantation. In addition, they must be tested to ensure that they are free from intestinal pathogens. Production methods should be consistent with the requirements for new biological drugs. The use of specialized equipment for preparation of the transplant material (Stomacher Lab Blender) is desirable over modified home (kitchen) appliances.

Synthetic bacterial culture derived from human feces creates additional issues to be resolved, such as the monitoring of the culture for contamination and stability of culture etc, and thus, requires special considerations that are not yet fully defined. BGTD has the capacity, and is willing, to work with sponsors to help determine an acceptable path forward.

Although the anecdotal evidence for MET is promising, it is only through rigorous clinical trials that its actual effectiveness, clinical utility and safety will be determined. Any clinical study of fecal transplantation or synthetic stool transplants will need to go through the process of a CTA to ensure the quality and safety standards expected of a new biological drug are met. Health Canada would like to be regarded as a partner in assisting in the rigor necessary for wide acceptance of emerging therapies as opposed to being considered a barrier to new approaches and is willing to continue advising in this process.

\section{PRIORITIES FOR FUTURE STUDIES}

The following four priority areas for research and action were identified.

\section{Better C difficile epidemiological data are needed}

To effectively design fecal transplantation and related programs, there is a need for a more comprehensive epidemiological understanding of CDI in Canada. Specifically, community-associated CDI and recurrent or refractory CDI must be better characterized. The influence of various strain types on the progression to, and outcome of, recurrent CDI should be explored. These points can only be addressed if there is a new and/or improved mechanism of communication among community clinicians, hospitals and national surveillance programs.

\section{Improved and more standardized methods for detecting recurrent} CDI are needed

Ultimately, to determine efficacy of fecal transplantation and related therapies, such as synthetic stool transplantation, detection of the key outcome of interest in clinical studies (ie, further recurrences of CDI) must be adequately captured. Presently, clinical studies involving patients with recurrent CDI are hampered by vagueness of clinical symptoms and sometimes from difficulty in distinguishing recurrence from postinfectious irritable bowel syndrome. Furthermore, laboratory testing for $\mathrm{C}$ difficile varies across the country, with many institutions still using the more affordable but less sensitive immunoassay for toxins $\mathrm{A} / \mathrm{B}$ and others having switched to highly sensitive polymerase chain reaction assays. Until there is consensus on the clinical case definition for recurrent CDI and standardization of laboratory testing methods, progress in studying therapies for the disease will be limited. If it is not possible to derive a consensus for the clinical case definition, then a mechanism for centralized review of cases could be established.

\section{Donor screening must be standardized}

Several aspects of donor screening need to be addressed and formalized. A standard operating procedure for donor screening, including a consensus screening panel, should be developed and established in collaboration with Health Canada, the United States Food and Drug Administration and the medical centres with experience in MET. It should align with the current expectations of regulatory agencies, and be acceptable to patients and clinicians. Efforts must be made to support innovative approaches that aim to decrease the expense and potential risks of real-time donor screening. These include exploring the use of frozen stool from a single, screened donor and continuing to study (and optimize) synthetic stool transplants. 


\section{Preparation and administration of MET products should be standardized}

To ensure consistency in the therapeutic product being delivered to patients, the methodologies for preparing and delivering MET should be agreed upon. Ideally, stability testing of the final product, as well as head to head comparisons of administration routes, would guide this effort. It would also satisfy Health Canada's requirements for a new biological drug product. A particularly important issue is whether freezing alters its efficacy. How stability testing for a product such as stool is best performed is debatable; the traditional parameters used to describe a drug (pharmacokinetics, bioavailability, toxicity, etc) do not apply to fecal material, except that some measure of batch-to-batch uniformity might. Use of prescreened, select donors provides a key advantage in the ability to administer material expeditiously and in the reduction of donor screening costs. Another potential benefit of this method is the potential reproducibility of microbiota it might provide. Use of chemostat cultures to produce 'synthetic stool' could provide even more reproducibility and the consensus was that this may represent the best way forward.

\section{Other research questions that need to be addressed}

Several future research avenues related to MET were identified during the meeting. These include the following:

a) What are the effects of dietary changes on the microbiome? Understanding this may influence how we counsel and monitor patients after MET.

b) What is the role of MET on other gastrointestinal colonizing pathogens, such as vancomycin-resistant enterococci and carbapenem-resistant Enterobacteriaceae? Can this strategy potentially decrease the incidence of other hospital-associated infections, thereby increasing patient safety?

c) What is the role of MET in other diseases and health conditions, such as inflammatory bowel disease, obesity, atopy, regressive autism and depression? Human microbiome research continues to reveal surprising correlations between the gut microbiota and a variety of conditions and health states.

d) How can we apply our learning from studying traditional fecal transplantation to implementing synthetic stool transplants? If synthetic stool transplants can be perfected and streamlined, they may well be adopted as the preferred therapy for treating diseases associated with an aberrant microbiota.

\section{SUMMARY}

Treatment of recurrent CDI is a recognized problem that was identified by the SHEA-IDSA Expert Panel on CDI as an important area needing further research (37). The present panel believes one priority should be to determine the best approach to restore intestinal microbiota homeostasis in a valid and standardized way. The use of MET to treat disease would represent a paradigm shift in disease management. Several challenges lie ahead in pursuing this new treatment, including the need to comply with regulatory requirements that were developed for products that are not analogous to fecal material. However, the desire and willpower to overcome these challenges exists in Canada and, if only for patient care, these must prevail.

ACKNOWLEDGEMENTS: This meeting was sponsored by CIHR (jointly by the Institute of Infection and Immunity, and the Institute of Nutrition, Metabolism, and Diabetes) and the Gastrointestinal Diseases Research Unit at Queen's University and organized by Drs Petrof and Allen-Vercoe. The authors thank all the other participants of the meeting, whose input and comments during the breakout sessions contributed greatly to the content of this summary paper: Drs Paul Beck (University of Calgary), Premysl Bercik (McMaster University), Judith Bray (CIHR-III), Jeremy Burton (Lawson Health Research Institute), Kenneth Croitoru (University of Toronto), Kenneth Dewar (McGill University), Martin Kalmokoff (Agri-Food Canada), Douglas Inglis (Agri-Food Canada),
Thomas Louie (University of Calgary), Karen Madsen (University of Alberta), Amee Manges (McGill University), Mark Miller (McGill University), Michael Mulvey (National Laboratory, University of Manitoba), Marc Ouellette (CIHR-III), Dylan Pillai (University of Calgary), Susan Poutanen (University of Toronto), Mark Ropeleski (Queens University), Phillip Sherman (CIHR-INMD), Michael Silverman (University of Toronto), Theodore Steiner (University of British Columbia), Ms Rohini Soni (CCFC), Mr David Hartell and Ms Mary-Jo Makarchuk (CIHR-INMD). The authors also thank Ms Tera Dojczman for her excellent administrative assistance and Ian Spreadbury for editorial assistance.

DISCLOSURES: Christine Lee serves on the Advisory Board for Optimer. All other authors have no financial disclosures or conflicts of interest to declare.

\section{REFERENCES}

1. Bartlett JG, Gerding DN. Clinical recognition and diagnosis of Clostridium difficile infection. Clin Infect Dis 2008;46(Suppl 1):S12-18.

2. Loo VG, Poirier L, Miller MA, et al. A predominantly clonal multiinstitutional outbreak of Clostridium difficile-associated diarrhea with high morbidity and mortality. N Engl J Med 2005;353:2442-9.

3. Pepin J, Valiquette L, Alary ME, et al. Clostridium difficile-associated diarrhea in a region of Quebec from 1991 to 2003: A changing pattern of disease severity. CMAJ 2004;171:466-72.

4. Gravel D, Miller M, Simor A, et al. Health care-associated Clostridium difficile infection in adults admitted to acute care hospitals in Canada: A Canadian Nosocomial Infection Surveillance Program Study. Clin Infect Dis 2009;48:568-76.

5. Bakken JS. Fecal bacteriotherapy for recurrent Clostridium difficile infection. Anaerobe 2009;15:285-9.

6. Pepin J, Alary ME, Valiquette L, et al. Increasing risk of relapse after treatment of Clostridium difficile colitis in Quebec, Canada. Clin Infect Dis 2005;40:1591-7.

7. Chang JY, Antonopoulos DA, Kalra A, et al. Decreased diversity of the fecal microbiome in recurrent Clostridium difficile-associated diarrhea. J Infect Dis 2008;197:435-8

8. Im GY, Modayil RJ, Lin CT, et al. The appendix may protect against Clostridium difficile recurrence. Clin Gastroenterol Hepatol 2011;9:1072-7.

9. Khoruts A, Dicksved J, Jansson JK, Sadowsky MJ. Changes in the composition of the human fecal microbiome after bacteriotherapy for recurrent Clostridium difficile-associated diarrhea. J Clin Gastroenterol 2010;44:354-60.

10. Tvede M, Rask-Madsen J. Bacteriotherapy for chronic relapsing Clostridium difficile diarrhoea in six patients. Lancet 1989;1:1156-60.

11. Gough E, Shaikh H, Manges AR. Systematic review of intestinal microbiota transplantation (fecal bacteriotherapy) for recurrent Clostridium difficile infection. Clin Infect Dis 2011;53:994-1002.

12. Rohlke F, Surawicz CM, Stollman N. Fecal flora reconstitution for recurrent Clostridium difficile infection: Results and methodology. J Clin Gastroenterol 2010;44:567-70.

13. van Nood E, Speelman P, Kuijper EJ, Keller JJ. Struggling with recurrent Clostridium difficile infections: Is donor faeces the solution? Euro Surveill 2009;14:19316.

14. Metcalf D, Avery BP, Janecko N, Matic N, Reid-Smith R, Weese JS. Clostridium difficile in seafood and fish. Anaerobe 2011;17:85-6.

15. Metcalf DS, Costa MC, Dew WM, Weese JS. Clostridium difficile in vegetables, Canada. Lett Appl Microbiol 2010;51:600-2.

16. Weese JS, Avery BP, Rousseau J, Reid-Smith RJ. Detection and enumeration of Clostridium difficile spores in retail beef and pork. Appl Environ Microbiol 2009;75:5009-11.

17. Rupnik M. Clostridium difficile: (Re)emergence of zoonotic potential. Clin Infect Dis 2010;51:583-4.

18. Bauer MP, Notermans DW, van Benthem BH, et al. Clostridium difficile infection in Europe: A hospital-based survey. Lancet 2011;377:63-73.

19. Goorhuis A, Bakker D, Corver J, et al. Emergence of Clostridium difficile infection due to a new hypervirulent strain, polymerase chain reaction ribotype 078. Clin Infect Dis 2008;47:1162-70.

20. Rupnik M, Widmer A, Zimmermann O, Eckert C, Barbut F. Clostridium difficile toxinotype V, ribotype 078, in animals and humans. J Clin Microbiol 2008;46:2146. 
21. Castellarin M, Warren RL, Freeman JD, et al. Fusobacterium nucleatum infection is prevalent in human colorectal carcinoma. Genome Res 2012;22:299-306.

22. Kostic AD, Gevers D, Pedamallu CS, et al. Genomic analysis identifies association of Fusobacterium with colorectal carcinoma. Genome Res 2012;22:292-8.

23. Hamilton MJ, Weingarden AR, Sadowsky MJ, Khoruts A. Standardized frozen preparation for transplantation of fecal microbiota for recurrent Clostridium difficile infection. Am J Gastroenterol 2012;107:761-7.

24. Silverman MS, Davis I, Pillai DR. Success of self-administered home fecal transplantation for chronic Clostridium difficile infection. Clin Gastroenterol Hepatol 2010;8:471-3.

25. Petrof E, Gloor G, Vanner S, Weese J, Allen-Vercoe E. Repoopulating the gut: Use of synthetic stool to cure recurrent $\mathrm{C}$ difficile infection. Canadian Digestive Diseases Week, February 23 to 27, 2012, Vancouver, British Columbia (Abst).

26. Macfarlane GT, Macfarlane S, Gibson GR. Validation of a threestage compound continuous culture system for investigating the effect of retention time on the ecology and metabolism of bacteria in the human colon. Microb Ecol 1998;35:180-7.

27. Mäkivuokko H, Nurminen P. In vitro methods to model the gastrointestinal tract. In: Ouwehand AC, Vaughan EE, eds. Gastrointestinal Microbiology, 1st edn. New York: Taylor \& Francis, 2006:237-52.

28. Mai V, Greenwald B, Morris JG Jr, Raufman JP, Stine OC. Effect of bowel preparation and colonoscopy on post-procedure intestinal microbiota composition. Gut 2006;55:1822-3.
29. Gloor GB, Hummelen R, Macklaim JM, et al. Microbiome profiling by illumina sequencing of combinatorial sequence-tagged PCR products. PLoS One 2010;5:e15406.

30. Huse SM, Dethlefsen L, Huber JA, Mark WD, Relman DA, Sogin ML. Exploring microbial diversity and taxonomy using SSU rRNA hypervariable tag sequencing. PLoS Genet 2008;4:e1000255.

31. Caporaso JG, Kuczynski J, Stombaugh J, et al. QIIME allows analysis of high-throughput community sequencing data. Nat Methods 2010;7:335-6.

32. Muegge BD, Kuczynski J, Knights D, et al. Diet drives convergence in gut microbiome functions across mammalian phylogeny and within humans. Science 2011;332:970-4.

33. Glass EM, Wilkening J, Wilke A, Antonopoulos D, Meyer F. Using the metagenomics RAST server (MG-RAST) for analyzing shotgun metagenomes. Cold Spring Harb Protoc 2010;2010(1):db.

34. Parks DH, Beiko RG. Identifying biologically relevant differences between metagenomic communities. Bioinformatics 2010;26:715-21.

35. Skloot R. The Immortal Life of Henrietta Lacks. New York: Crown, 2010.

36. Hawkins AK, O’Doherty KC. "Who owns your poop?": Insights regarding the intersection of human microbiome research and the ELSI aspects of biobanking and related studies. BMC Med Genomics 2011;4:72.

37. Cohen SH, Gerding DN, Johnson S, et al. Clinical practice guidelines for Clostridium difficile infection in adults: 2010 update by the society for healthcare epidemiology of America (SHEA) and the infectious diseases society of America (IDSA). Infect Control Hosp Epidemiol 2010;31:431-55. 


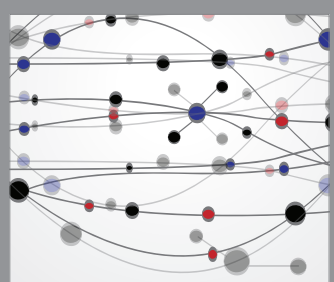

The Scientific World Journal
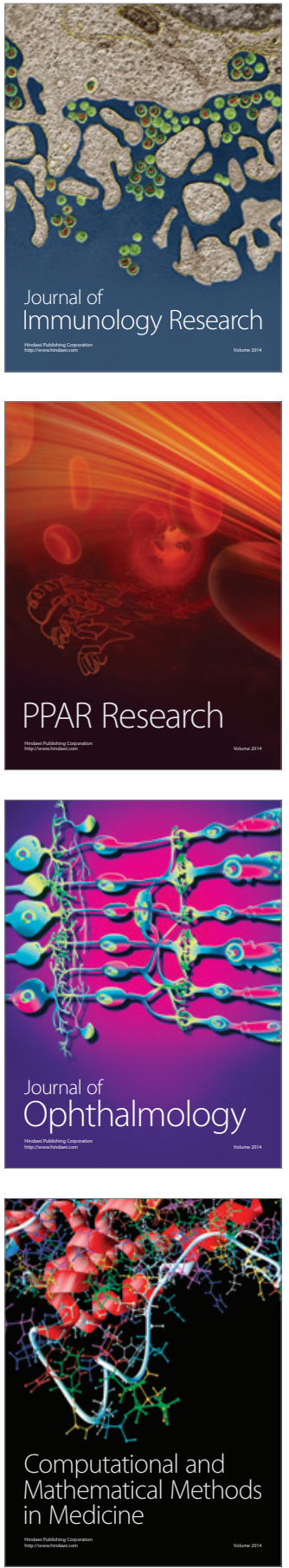

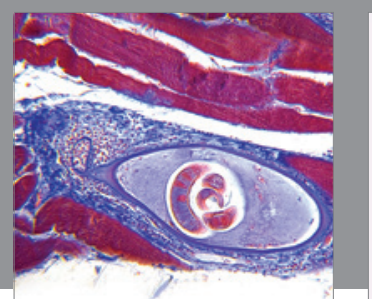

Gastroenterology Research and Practice

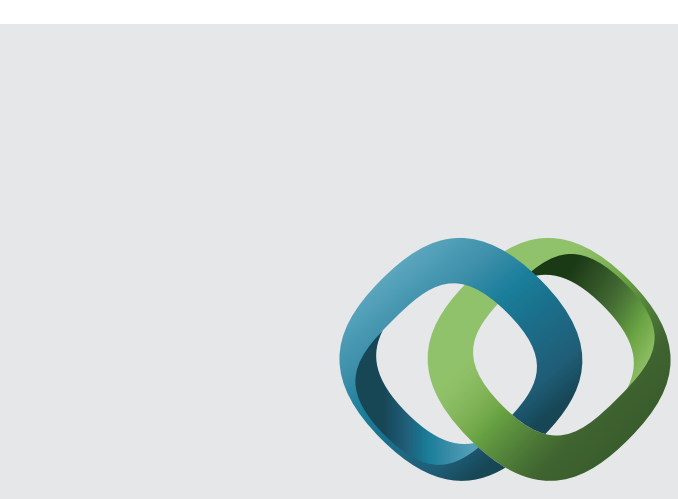

\section{Hindawi}

Submit your manuscripts at

http://www.hindawi.com
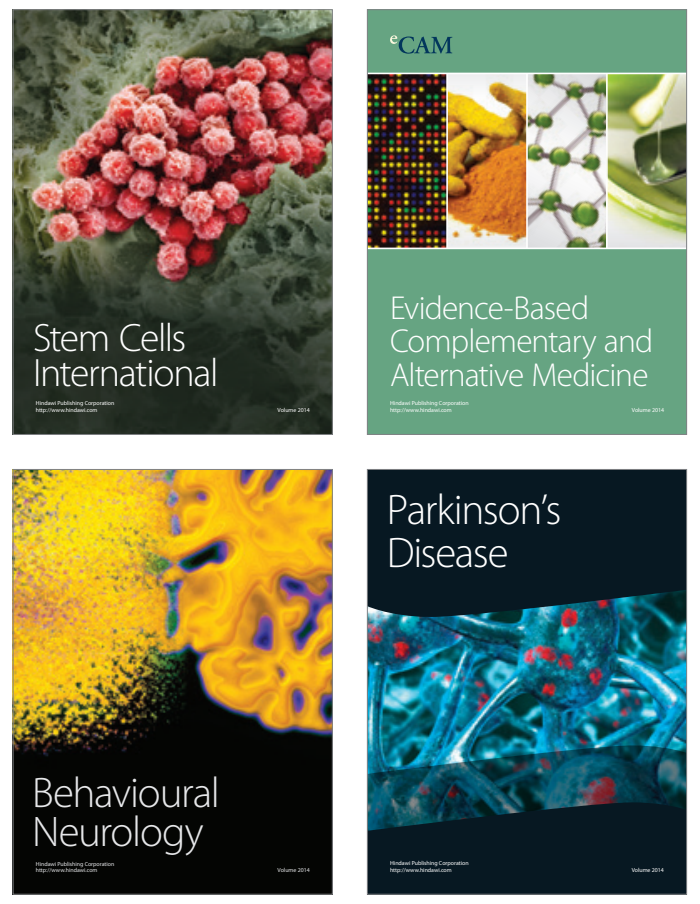
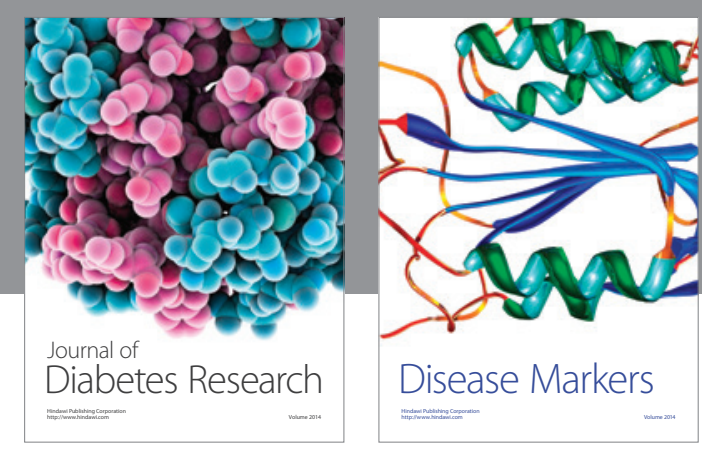

Disease Markers
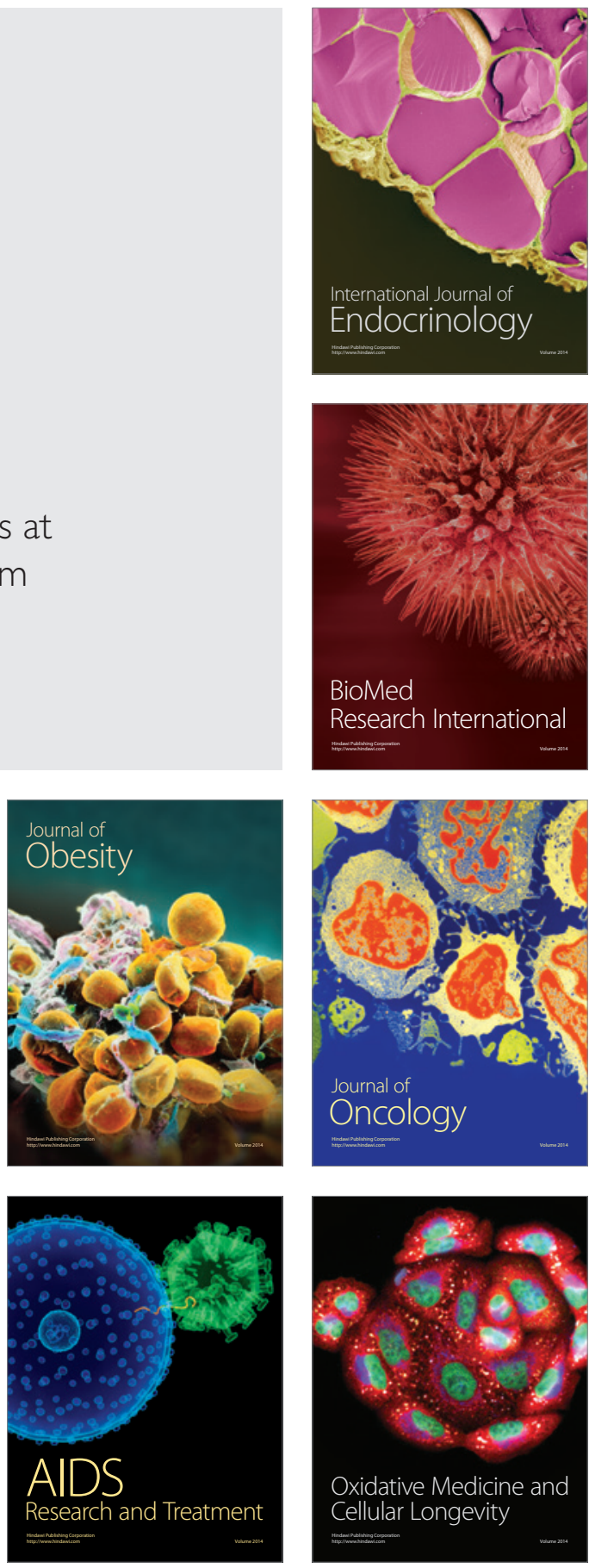